\title{
AS VEREDAS DE BUDA
}

\author{
Alexsânder Nakaóka Elias $\mathbb{D}$
}

Pós-doutorando em Antropologia Social (NAVISUAL/UFRGS)

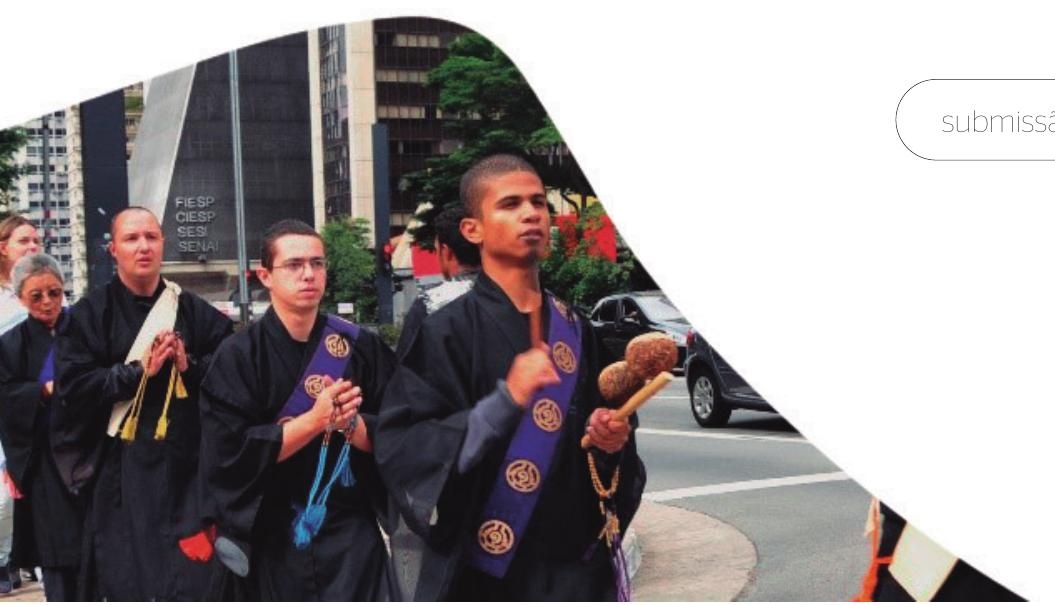


O início do processo migratório entre Japão e Brasil data da primeira década do século XX, quando o navio Kasato Maru zarpou do porto de Kobe e, após 52 dias, atracou no cais de Santos trazendo a bordo 781 pessoas, divididas em 165 famílias (Usarski 2002, Correia 2008). Do dia 18 de junho de 1908 para cá, são mais de 112 anos de uma contínua imigração, marcada por ondas mais ou menos intensas, mas sempre existentes, que constituem uma comunidade heterogênea e espalhada por todo o país. Sobre esse processo migratório, tema caro à Antropologia Urbana, é fundamental dizer que a chegada dos japoneses e a formação dos grupos de nikkeis gerou um fenômeno no sentido inverso, isto é, a emigração de brasileiros, em sua maioria com ascendência nipônica, para a "Terra do Sol Nascente". Nos dois casos, tais migrações foram acarretadas por momentos de crise e possuem o "trabalho" (ou a busca por ele) como característica comum: de um lado, os japoneses vieram para o Brasil inicialmente pela necessidade de aliviar a tensão socioeconômica no país, resultante de uma grande densidade/explosão demográfica e, posteriormente, devido aos períodos de escassez entre as duas grandes guerras. Por outro lado, o movimento inverso se deu devido à (eterna) instabilidade e desamparo socioeconômico em que vivemos, havendo no Japão cerca de 180.923 decasséguis ${ }^{1}$, de acordo com dados publicados em 2017 pela Bloomberg².

Embora exista uma importante questão relativa à "identidade", uma vez que os brasileiros com ascendência nipônica são vistos com decasséguis no Japão, ou seja, não são "legítimos" japoneses"; enquanto os japoneses e suas proles são considerados como nikkeis no Brasil, isto é, não são “totalmente" brasileiros (Hikiji \& Kishimoto 2008), o trajeto mais potente e instigante parece ser o de investir nessa via de mão dupla que envolve não apenas pessoas que cruzam barreiras geográficas, mas também o trânsito de relações de sociabilidade as mais diversas (dinheiro, informações, fotografias, vídeos, afetos, experiências etc.).

Dessa forma, opto por utilizar e reiterar a presença de um estilo de vida compartilhado pelos decasséguis e pelos nikkeis. Koury (2010) e Velho (1995) dizem, a partir das definições de culturas "objetivas" e "subjetivas" de Simmel (1998), que o estabelecimento do estilo de vida está relacionado ao processo de individualidade na sociedade, em especial, às formas de sociabilidades urbanas. Para

1 Decasségui ou dekasegi é resultado da junção dos termos "deru”, que significa "sair" e "kasegu", que significa "para trabalhar" ou "para ganhar dinheiro trabalhando".

2 https://www.bloomberg.com 
Koury (2010), a cultura subjetiva é formada na troca interacional entre indivíduos, o que permite o aumento da diferenciação entre cada um deles e nos grupos e arranjos sociais por eles organizados, fator que complexifica a relação e a vida na cidade. Por sua vez, Velho (1995: 231) chama a atenção não apenas para a "coexistência de diferentes visões de mundo e estilos de vida", mas para a necessidade de se perceber "como os indivíduos lidam e se deslocam entre códigos e mundos diferenciados quanto aos valores, orientações e sistemas classificatórios”. Seguindo o autor, trato aqui de um processo contemporâneo que agrega indivíduos dos mais variados estratos e procedências, assim como ocorre com os nikkeis, cujos sujeitos exercem as mais diversas funções sociais. Todas essas questões partem, assim, do campo de debate da Antropologia Urbana, refletindo sobre a existências das "sociedades complexas" (Peirano 1983, Velho 1981,1994), isto é, analisando a urbe em toda a sua pluralidade, composta por um conjunto heteróclito de formas de sociabilidade e experiências.

Nessa direção, é fundamental mencionar a existência de outro aspecto nas comunidades nikkeis, que consiste no fato delas apresentarem, simultaneamente, uma noção de pertencimento local e global. Local, pelo fato de cada família, dependendo das regiões de fixação, apresentar particularidades e expressar com maior ou menor intensidade as características desse ethos (Bateson 1936) japonês, como se formassem espécies de "clãs" que incluem não somente laços de consanguinidade, mas também de afinidade. Depois, existe uma relação global, já que comunidades nikkeis/decasséguis são formadas não apenas no Brasil e no Japão, mas em todo o mundo, revelando as dimensões transnacionais dessa mesma identidade. Para Velho (1995), as inovações econômicas e tecnológicas, que foram aceleradas a partir do século XVIII (com a Revolução Industrial e o Capitalismo), mas cujas origens remontam aos séculos XV e XVI, geraram "um processo inédito de globalização ao estabelecerem vínculos econômicos, políticos e culturais entre quase todas as grandes regiões do planeta". Aqui, "tanto a liberdade individual quanto a identidade singular de grupos situamse num mundo de relações cujas fronteiras, em muitos casos, podem ser planetárias" (Velho, 1995: 230) e esse jogo de relações não se estabelece sem diferenciações e momentos de crise e ruptura. Como ressalta Koury (2010: 46), existem sempre novas inserções e registros sociais que ampliam a cultura subjetiva de um dado espaço-tempo, compondo novas performances individuais e em grupo dentro de um estilo de vida existente.

No presente ensaio, portanto, busco dar a ver a comunidade Honmon Butsuryu-shu, primeira 
escola budista a aportar no nosso país (no mesmo navio Kasato Maru), com a qual realizei trabalhos de campo durante o mestrado e o doutorado. Aqui, destaco que acompanhei esse grupo no Brasil, tendo feito pesquisas nos templos das cidades paulistas de São Paulo, Campinas e Mogi das Cruzes, que possuem como característica serem fixados estrategicamente em cidades com grande presença de nikikeis, seguindo o próprio processo de migração e estabelecimento dos japoneses no país. Também participei de uma caravana composta por sacerdotes e adeptos, japoneses e brasileiros, que realizou uma peregrinação pelo Japão (onde existem mais de 300 templos da HBS), Índia e Nepal (os dois últimos são os locais que abrigam os mitos primordiais do Budismo). A sequência de imagens escolhidas diz respeito, especificamente, a uma passeata realizada por monges, uma monja e alguns adeptos pela Avenida Paulista, coração financeiro de São Paulo, maior cidade do país. Esse tipo de prática (passeata) é comum na HBS do Brasil, pois possui o intuito de disseminar o mantra sagrado Namumyouhourenguekyou, recitado incessantemente ao longo da caminhada para criar elos com todos os seres "senscientes" que o escutam, o que, em um futuro distante, os conduzirão à Iluminação (Nirvana). 


\section{REFERÊNCIAS}

Bateson, Gregory. [1936] 2006. Naven: Um esboço dos problemas sugeridos por um retrato compósito, realizado a partir de três perspectivas, da cultura de uma tribo da Nova Guiné. São Paulo: EdUSP.

Correia, Kyouhaku. 2008. O que é primordial? Budismo 100 anos. São Paulo: Editora Rmc.

Hikiji, Rose Satiko Gitirana e Kishimoto, Alexandre. 2008. Nikkeis no Brasil, decasséguis no Japão: identidade e memória em filmes sobre migrações. Revista USP. 79: 144-164.

Koury, Mauro Guilherme Pinheiro. 2010. Estilo de vida e individualidade. Horizontes Antropológicos. 33: 41-53.

Peirano, Mariza. 1983. Etnocentrismo às avessas: o conceito de "sociedade complexa". Revista de Ciências Sociais. 26: 97-115.

Usarski, Frank. 2002. O budismo no Brasil. São Paulo: Editora Lorosae.

Velho, Gilberto. 1981. Individualismo e Cultura. Rio de Janeiro: Jorge Zahar.

Velho, Gilberto. 1994. Projeto e Metamorfose: antropologia das sociedades complexas. Rio de Janeiro: Jorge Zahar.

Velho, Gilberto. 1995. Estilo de vida urbano e modernidade. Estudos Históricos. 16: 227-234. 


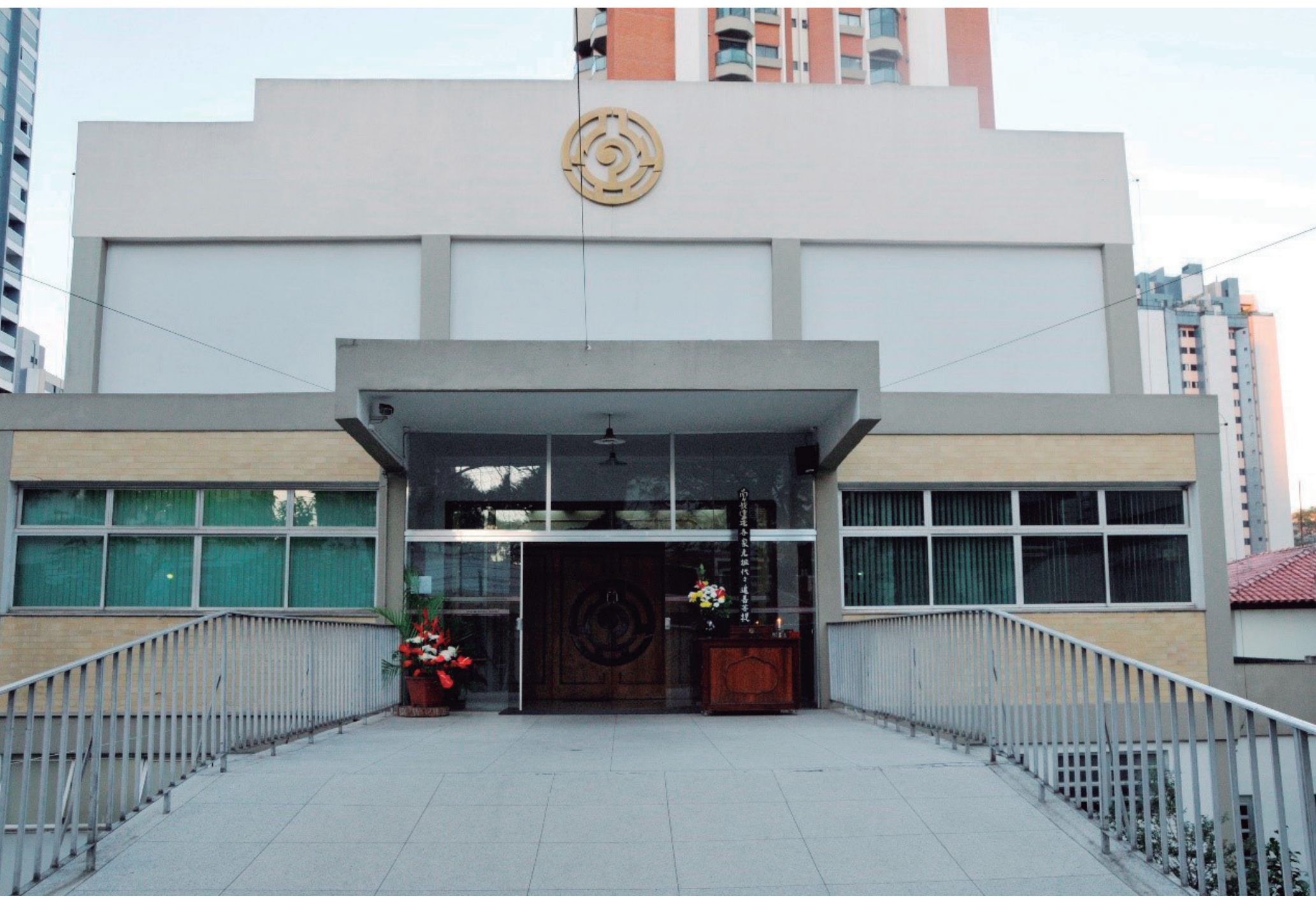

Imagem 1 - Vista frontal da nave (hondo) do Templo (Otera) Nikkyoji, sede nacional da escola HBS do Brasil, na cidade de São Paulo, antes da reforma. É aqui o local de residência dos monges e da monja que farão a passeata. Foto: Alexsânder Nakaóka Elias (2011). 




Imagem 2 - Agrupamento dos monges, monja e adeptos para o início da passeata, na Avenida Paulista. Foto: Alexsânder Nakaóka Elias (2011). 


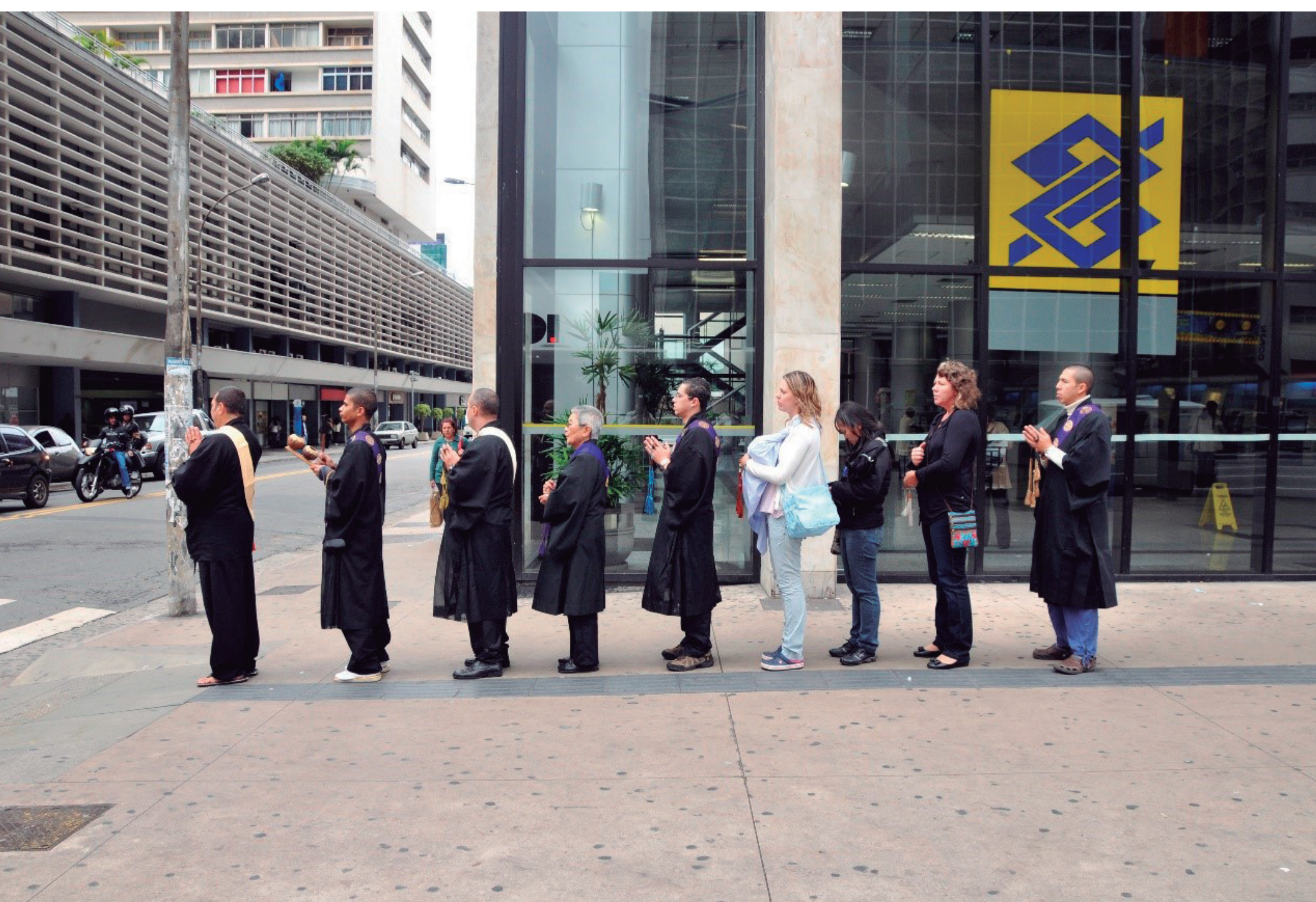

Imagem 3 - Passeata em fila indiana parada em frente ao Banco do Brasil. Foto: Alexsânder Nakaóka Elias (2011). 




Imagem 5 - Vista de trás da fila indiana, com os adeptos e religiosos aguardando o sinal abrir, próximos ao Vão do MASP. Nota-se um outro fotógrafo acompanhando, curioso, a passeata. Foto: Alexsânder Nakaóka Elias (2011). 


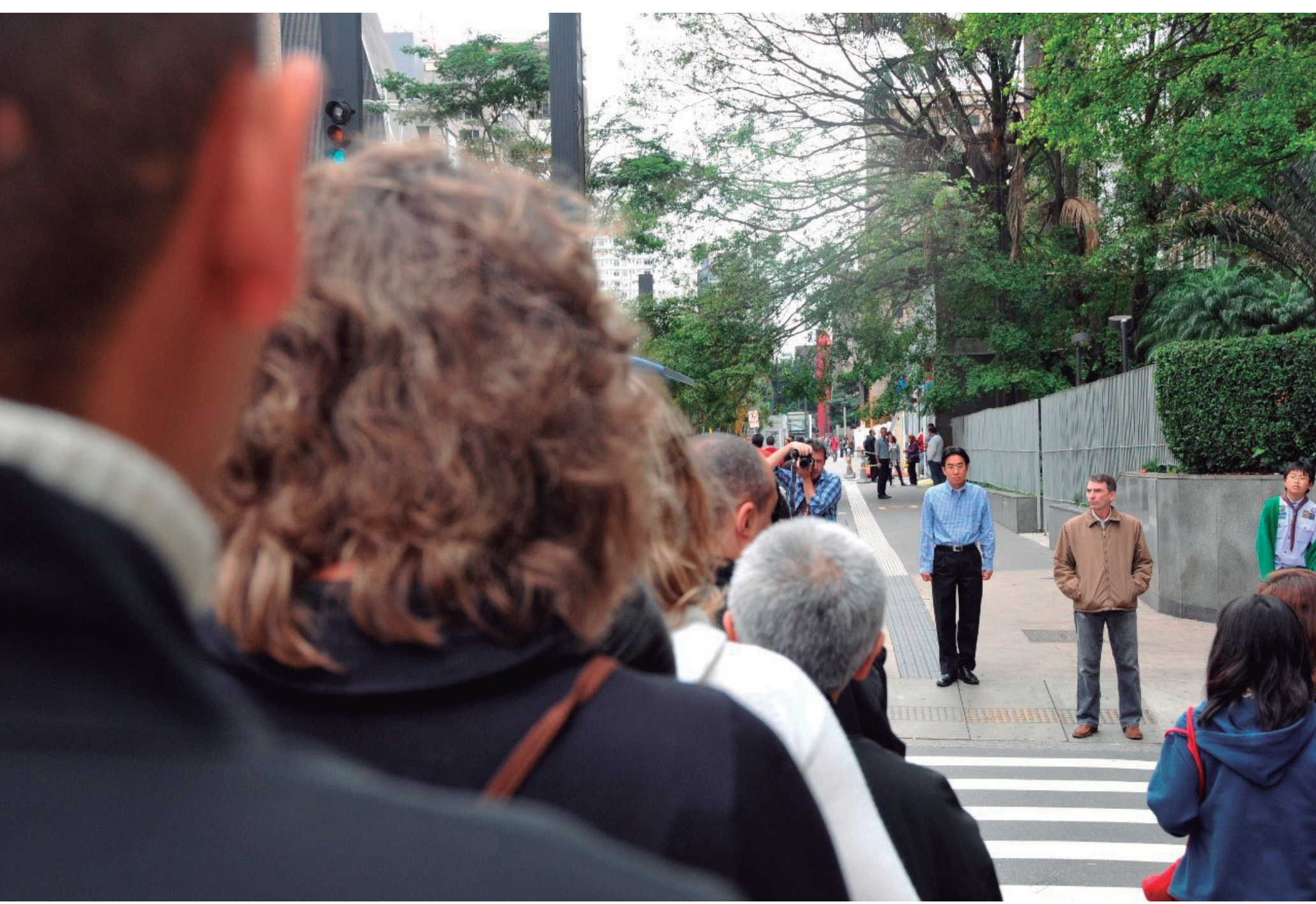

Imagem 6 - Vista de trás da fila indiana, com os adeptos e religiosos aguardando o sinal abrir. Agora, nota-se o mesmo fotógrafo registrando a passeata por outro ângulo. Foto: Alexsânder Nakaóka Elias (2011). 


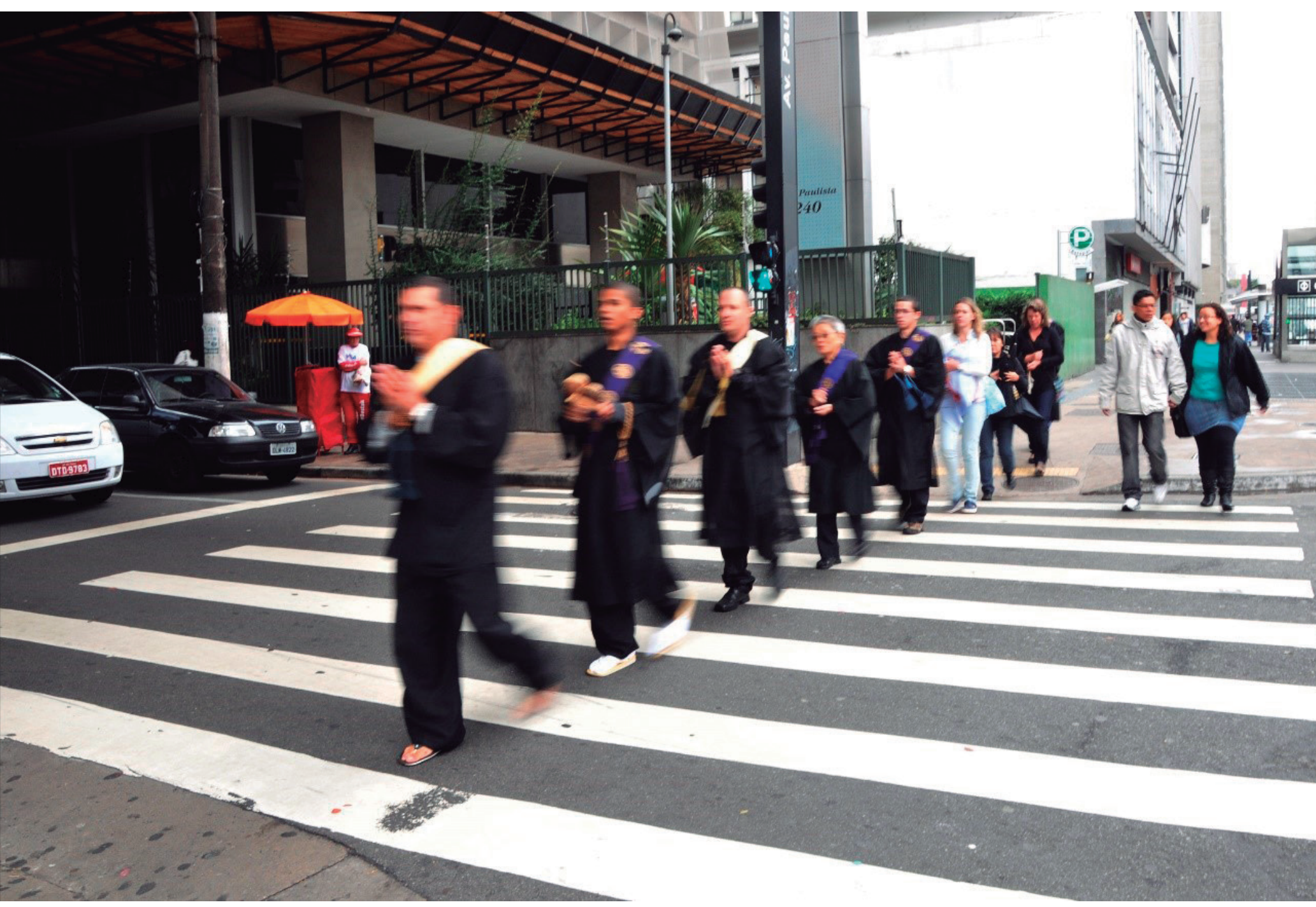

Imagem 8 - Adeptos cruzam a faixa de pedestres, com o sinal aberto. Foto: Alexsânder Nakaóka Elias (2011). 


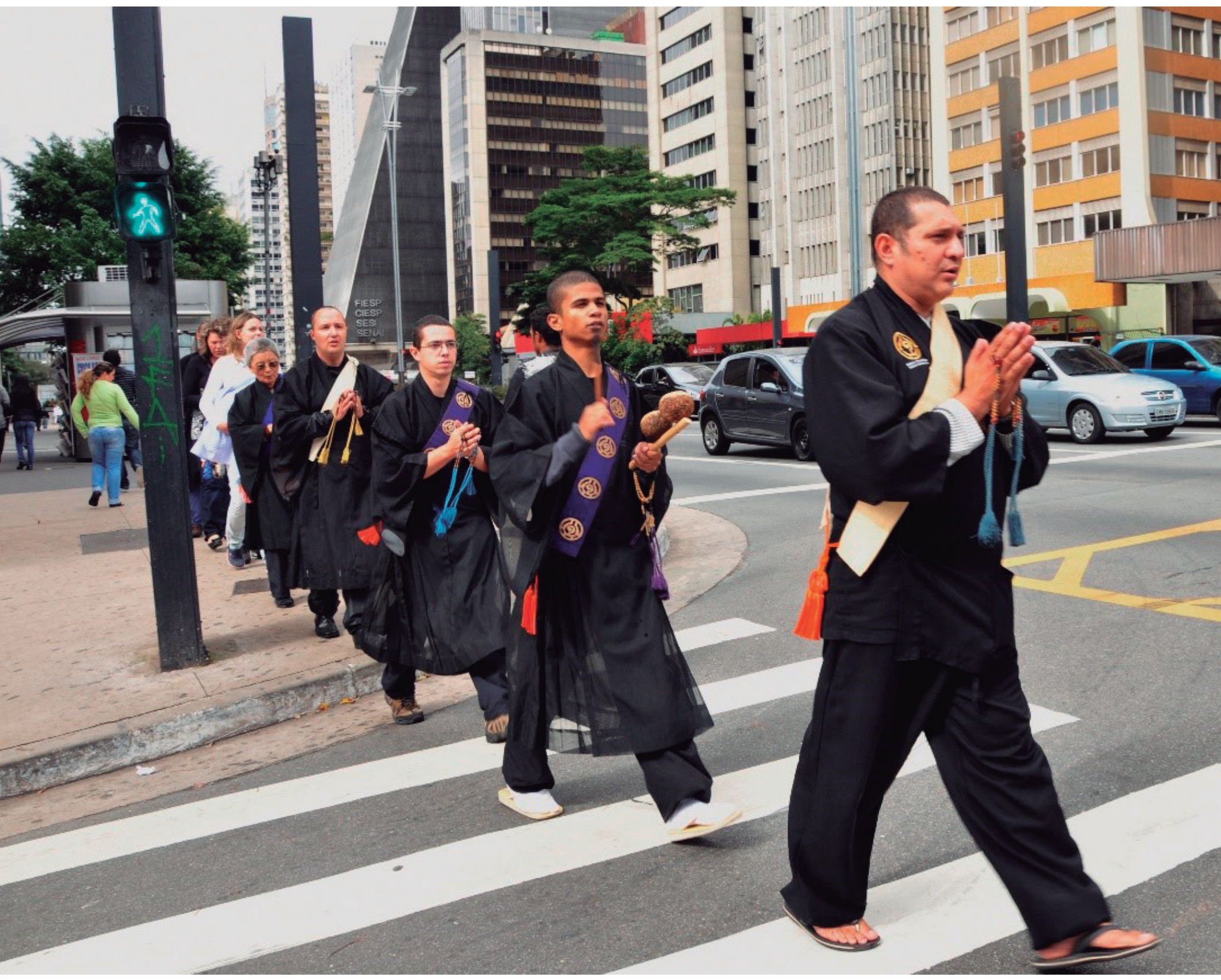

Imagem 9 - Adeptos cruzam a faixa de pedestres, com o sinal aberto. É possível notar o movimento dos lábios, entoando o Namumyouhourenguekyou, assim como a postura e os gestos manuais.

Foto: Alexsânder Nakaóka Elias (2011). 


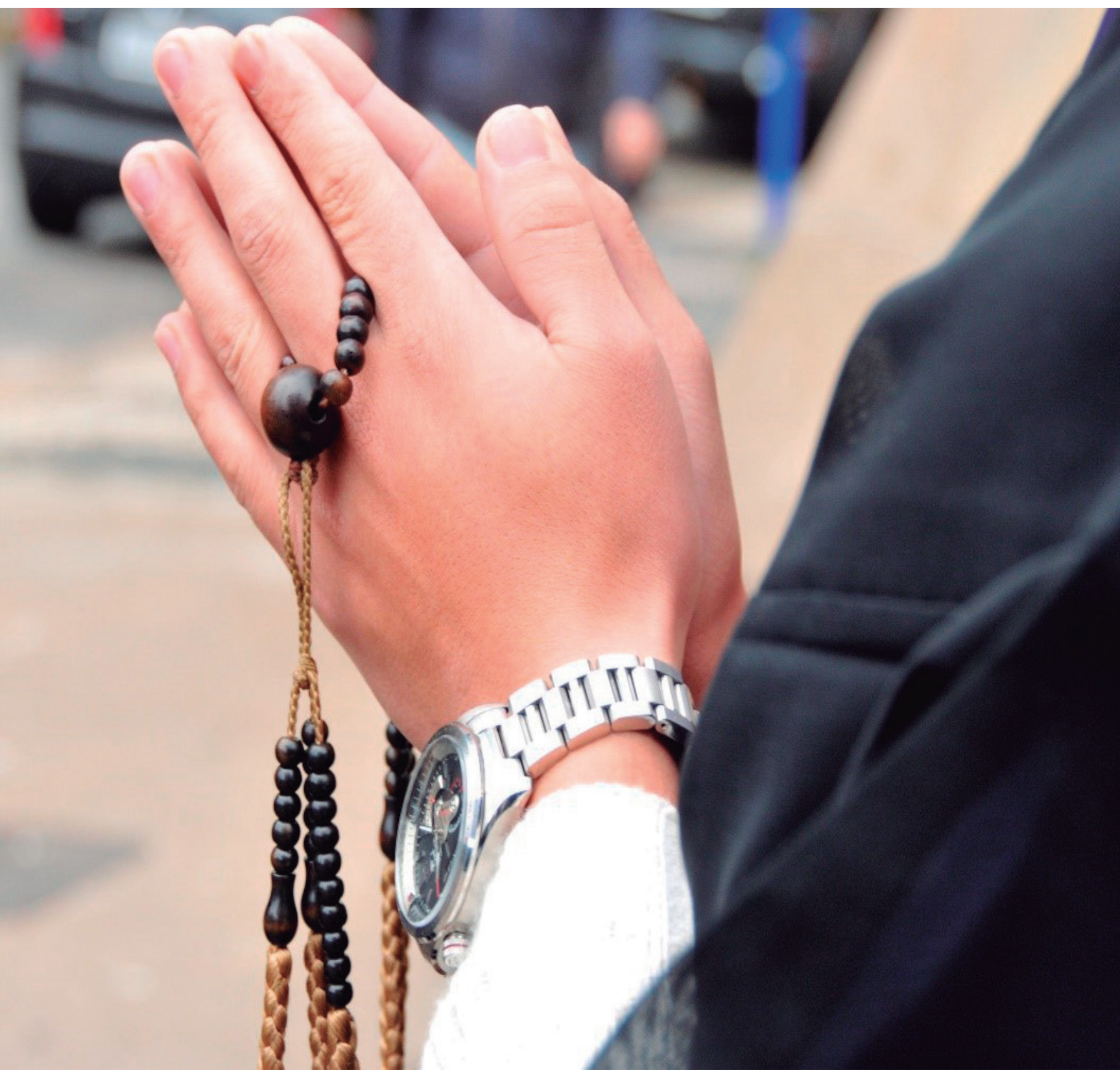

Imagem 10 - Plano detalhe da posição das mãos, durante a entoação do Namumyouhourenguekyou. Entre as mãos está o odyuzu (espécie de colar de contas ou "terço budista"). Foto: Alexsânder Nakaóka Elias (2011). 


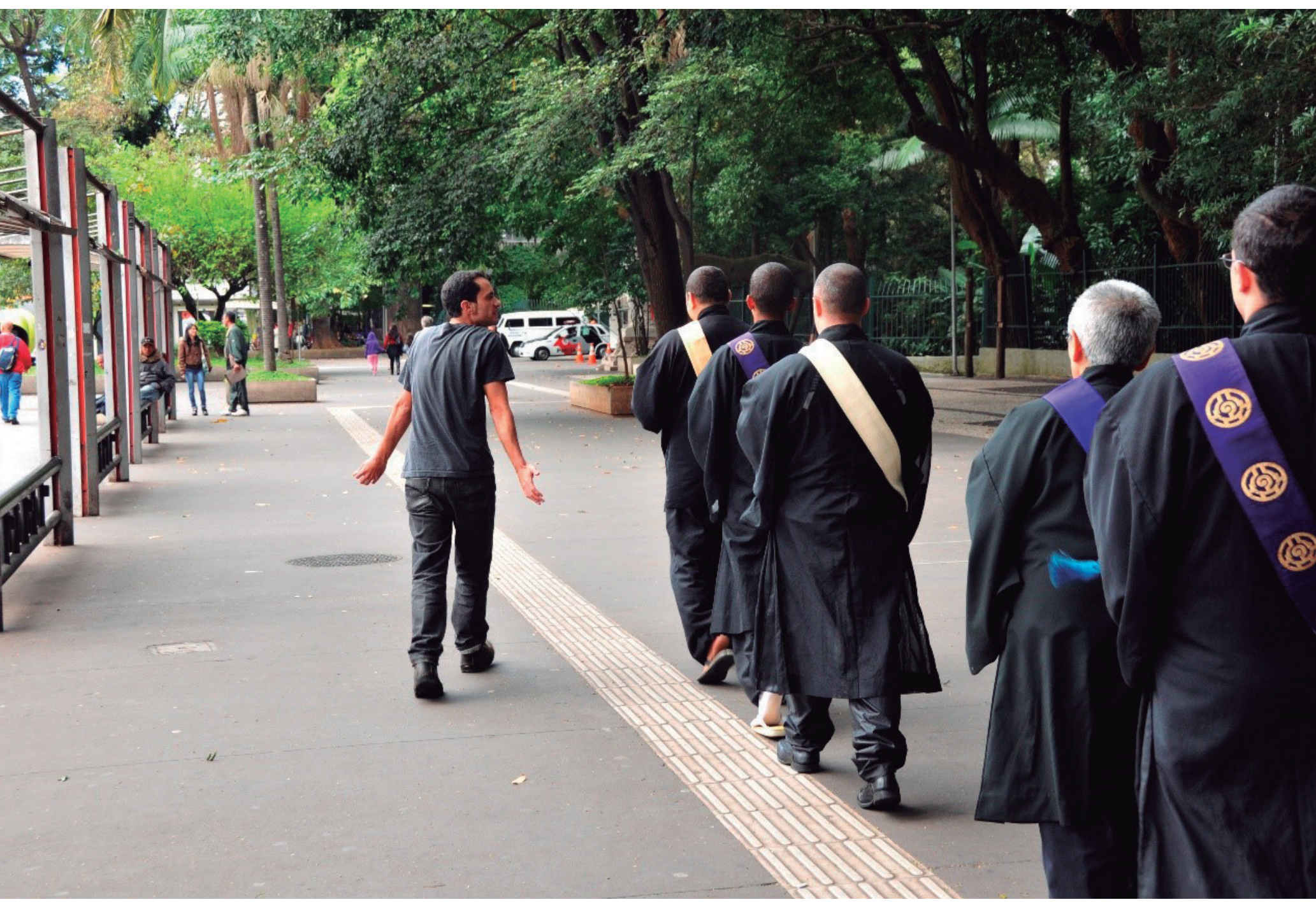

Imagem 11 - A passeata prossegue, quando um jovem se aproxima, um tanto agressivo. Foto: Alexsânder Nakaóka Elias (2011). 


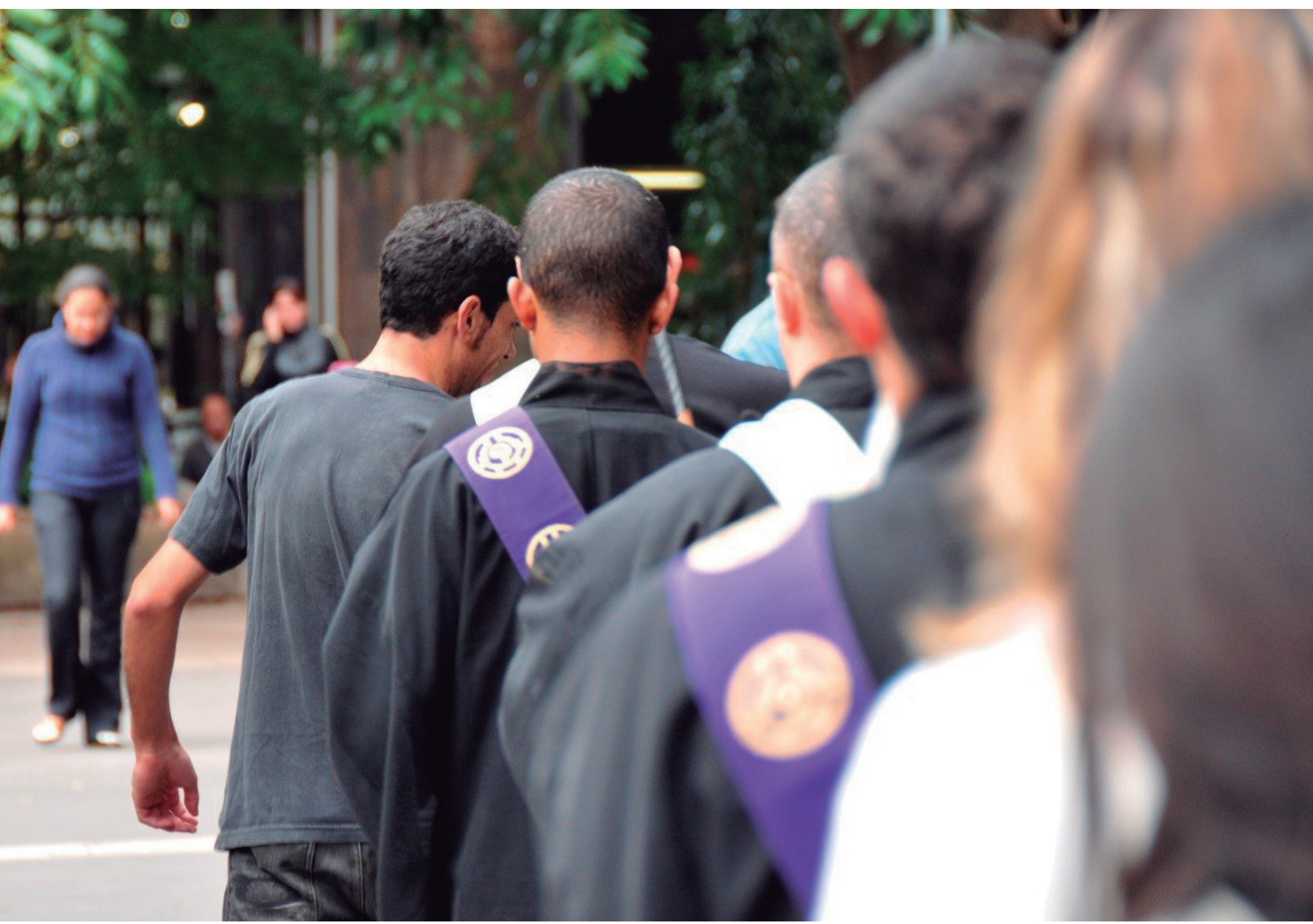

Imagem 13 - O transeunte aborda o Arcebispo Correia, passando de um lado para o outro. Foto: Alexsânder Nakaóka Elias (2011). 


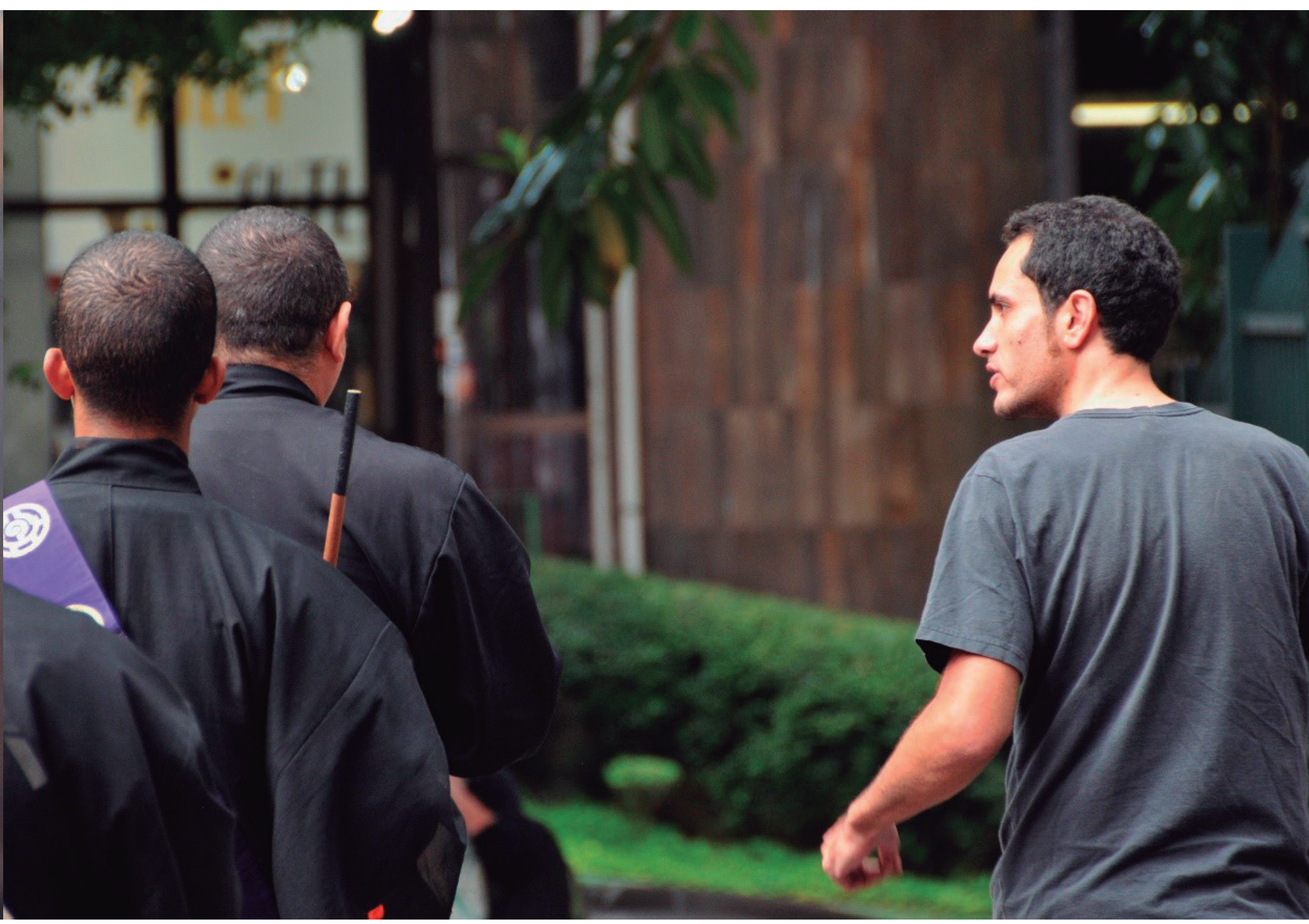

Imagem 14 - O jovem continua "acompanhando" a passeata, desferindo ofensas ao Arcebispo. Foto: Alexsânder Nakaóka Elias (2011). 


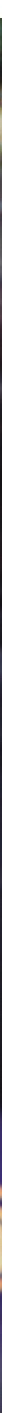

Imagem 15 - O Arcebispo continua a passeata, argumentando calmamente com o rapaz. Foto: Alexsânder Nakaóka Elias (2011). 


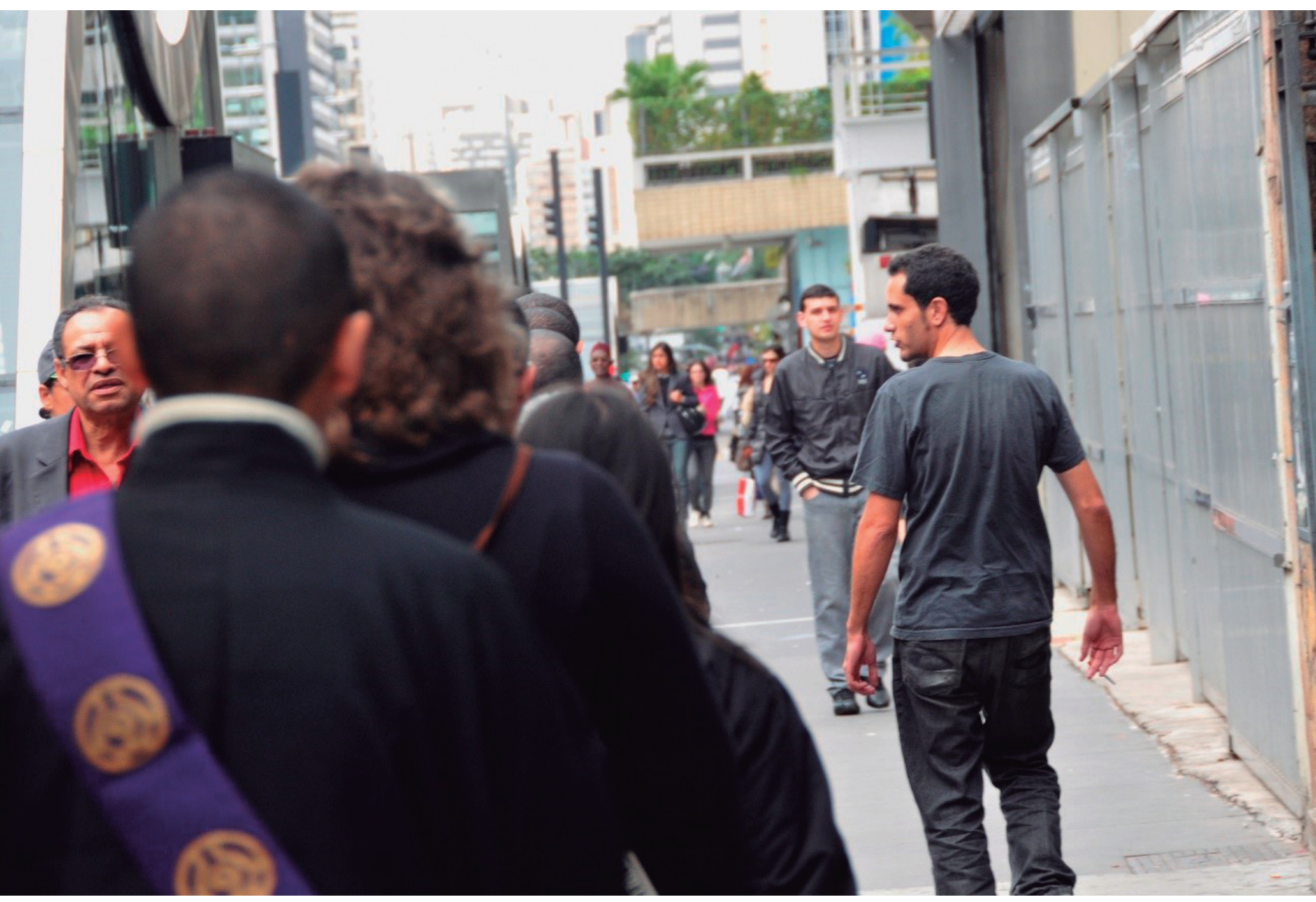

Imagem 16 - O jovem desiste da sua investida e vai embora, já que a sua postura agressiva não foi correspondida. Foto: Alexsânder Nakaóka Elias (2011). 


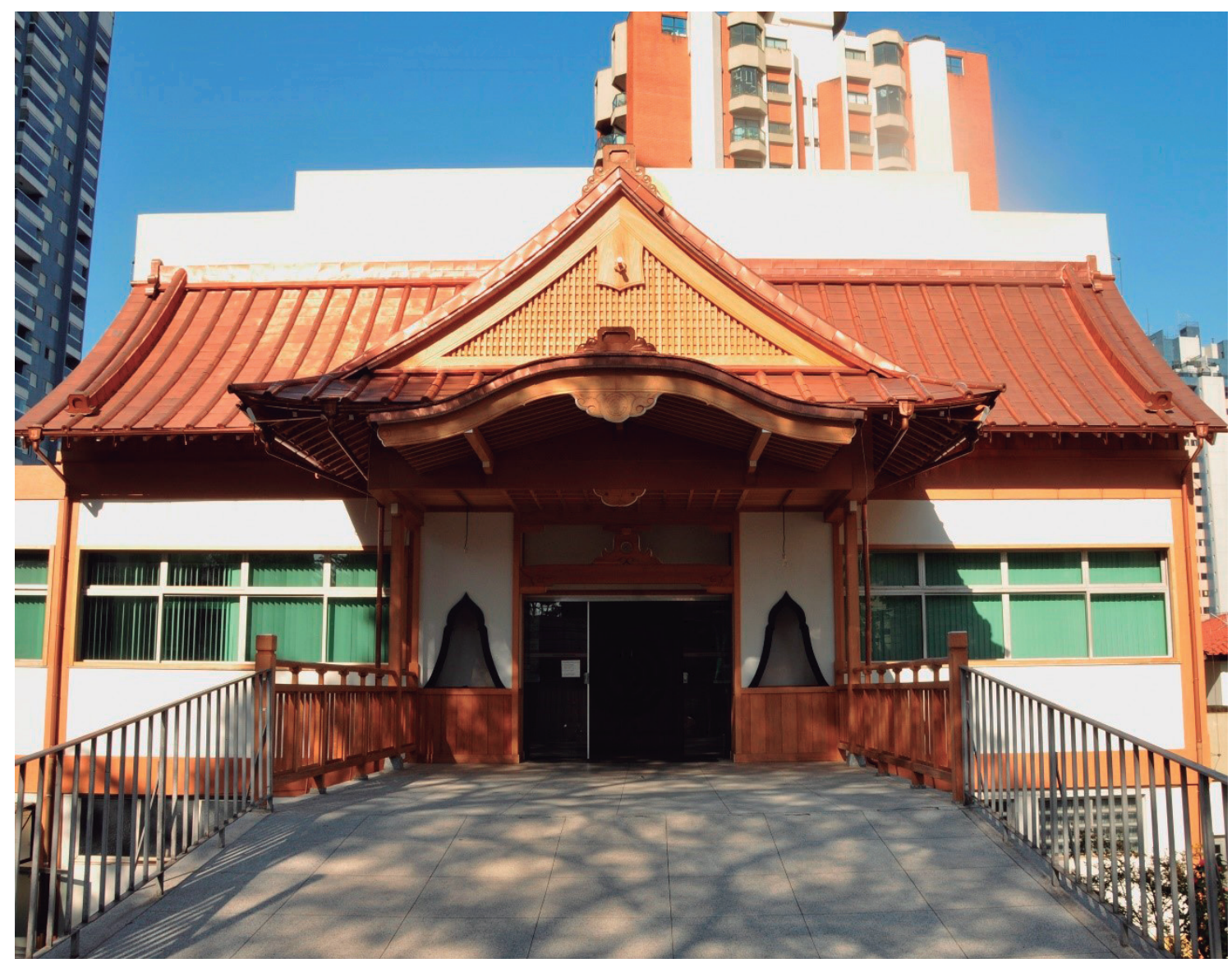

Imagem 17 - Após a passeata, os religiosos e adeptos retornam para a Catedral Nikkyoji. Essa tomada fotográfica dá a ver a fachada do Templo, após a reforma. Foto: Alexsânder Nakaóka Elias (2012). 